\title{
Gıda ve Beslenme Açısından D-Tagatoz
}

\author{
Hasan Yetim ${ }^{1,2}$, İsmail Hakkı Tekiner ${ }^{3,4}$ \\ 1** İstanbul Sabahattin Zaim Üniversitesi, Mühendislik Fakültesi, Gıda Mühendisliği Bölümü, İstanbul, Türkiye, (ORCID: 0000-0002-5388-5856), \\ hasan.yetim@izu.edu.tr \\ 2 İstanbul Sabahattin Zaim Üniversitesi, Helal Gıda Ar-Ge Merkezi, İstanbul, Türkiye \\ 3 İstanbul Sabahattin Zaim Üniversitesi, Sağlık Bilimleri Fakültesi, Beslenme ve Diyetetik Bölümü, İstanbul, Türkiye, (ORCID: 0000-0002-7248-2446), \\ ismail.tekiner@izu.edu.tr \\ ${ }^{4}$ İstanbul Sabahattin Zaim Üniversitesi, Lisansüstü Eğitim Enstitüsü, Gıda ve Beslenme Bölümü, İstanbul, Türkiye
}

(İlk Geliş Tarihi 5 Ekim 2021 ve Kabul Tarihi 6 Aralık 2021)

(DOI: $10.31590 /$ ejosat.1005082)

ATIF/REFERENCE: Yetim, H. \& Tekiner, İ.H. (2021). Gıda ve Beslenme Açısından D-Tagatoz. Avrupa Bilim ve Teknoloji Dergisi, (31), 193-198.

$\ddot{\mathbf{O} z}$

Tagatoz, genellikle süt ürünlerinde bulunan doğal ve altı karbonlu bir monosakkarit (ketoheksoz) şekerdir. İlk defa Gilbert Levin tarafından elde edilen Tagatozun tatlılık derecesi sükroza yakın ve kalorisi düşüktür. FAO ve WHO tarafindan 2001 yılından itibaren güvenilir kabul edilen D-Tagatoz (D-tag), son yıllarda artan şeker tüketimine bağlı obezite, diyabet, ağız sağlığı ve sindirim sistemi sorunlarına karşı alternatif bir tatlandırıcı olarak öne çıkmaktadır. Bu ilginin temelinde ise Tagatozun sükroza oranla daha az metabolize edilmesi, ince bağırsakta daha düşük emilimi, kolon mikroflorası tarafindan fermente edilebilmesi, antihiperglisemik oluşu, prebiyotik olarak gut sağlığını pozitif anlamda desteklemesi ile vücuttan idrar yoluyla uzaklaştırılabilmesi bulunmaktadır. Ayrıca, araştırmalar, Dtagatozun genotoksik etkisi olmadığını da göstermektedir. Glisemik indeksi düşük ve antidiyabetik etkisi olduğu kabul edilen DTagatozun doğal kaynakları dışında ticari olarak daha yüksek miktarlarda elde edilmesi, süt şekeri laktozun yapı taşı galaktozun, enzimatik ya da alkali izomerizasyonu ile sağlanmaktadır. Tagatoz üretimi amacıyla kullanılan ve Dünya süt ve süt ürünleri sektörünün en önemli yan ürünlerinden peynir altı suyunun yıllık üretimi 200 milyon ton civarındadır. Buradan üretilen süt şekeri galaktozun (laktozun parçalanma ürünü) ticari D-Tagatoza dönüştürülmesi, gıda sektörü için önemli bir çıkış yolu olarak görülmektedir. Sağlıklı ve doğal beslenme açısından getireceği faydaların dışında Dünya yapay tatlandıııcı pazarı büyüklüğünün 3.2 milyar dolar olduğu gerçeği de göz önüne alınırsa D-tagatozun, alternatif tatlandırıcı ve prebiyotik sektörleri için itici bir güç olacağını ifade etmek hatalı olmayacaktır. Ayrıca, son çalışmalar, D-Tagatozun tarım sektöründe bitki hastalıkları ile mücadelede antifungal agrokimyasal olarak kullanılabileceğini de göstermektedir. Sonuç olarak, bu çalışmada, D-tagatozun gıda mühendisliği ve beslenme bilimleri açısından yeri, önemi ve potansiyel uygulama alanlarının değerlendirilmesi amaçlanmıştır.

Anahtar Kelimeler: Gida, Beslenme, D-Tagatoz.

\section{D-Tagatose in Food and Nutrition}

\begin{abstract}
Tagatose is a naturally occurring six-carbon monosaccharide (ketohexose), which is generally found in dairy products. It was first proposed by Gilbert Levin, and has a similar texture to sucrose with a lower calorific value. D-Tagatose (D-tag) has recognized as safe status by FAO and WHO since 2001, and therefore gained significant attention in the recent years as an alternative sweetener for some health issues linked to excess sugar consumtion, including obesity, diabete, oral (tooth) health and gastrointestinal symptoms. On the basis of this interest, it has some advantageous characteristics, compared to sucrose, like lower metabolic activity, slow and incomplete absorption in the small intestine, low fermentability in the colon by microflora, antihyperglisemic, prebiotic promoting gut health, and easy-excretion from body via urine. Furthermore, the researches demonstrates that D-Tagatose has no genotoxic effect. D-Tagatose, an antidiabetic with low glycemic index, can also be obtained from the enzymatic or alkali isomerization of the milk sugars, galactose in high quantities commercially, other than natural sources. The whey is a by-product of the global milk and dairy sector with an annual production quantity of 200 million tonnes, and considered a potential raw-source for manufacturing tagatose. The conversion of milk sugar, galactose, into commercial D-tagatose therefore offers a way-out for the food industry. Except for its healthy and natural nutritional benefits, based on the fact that the global market of artificial sweeteners around 3.2 billion dollars, D-tagatose can play a pivotal role as a driving force for alternative sweeteners and prebiotic sector. In addition to that, the recent studies have indicated that D-tagatose can also be utilized as an agro-chemical to control fungal plant diseases in the agro-sector. Overall, the objective of this study was to evaluate the role, value and potential areas of application in both food engineering and nutritional sciences.
\end{abstract}

Keywords: Food, Nutrition, D-Tagatose.

*Sorumlu Yazar: hasan.yetim@izu.edu.tr 


\section{Giriş}

Şeker, bitkisel ve bazı hayvansal ürünlerde doğal olarak bulunan tüm monosakkarit ve disakkaritlerin genel adıdır. Bunlar, bitkilerde bulunan sükroz, glikoz ve früktoz ile süt ürünlerinde bulunan laktoz ve balda doğal olarak bulunan diğer karbonhidratlardır. Meyve-sebzeler başta olmak üzere tüm yeşil bitkiler, güneş 1şığını enerjiye dönüştüren doğal bir süreçle yani fotosentez yoluyla şeker üretirler. Tüm bitkilerde bulunan glikoz ve früktoz yine bitki tarafından sükroza dönüştürülür ve bunlar, canlılar için besin enerjisinin temelini oluştururlar (Altınışık, 2010). Ana besin gurubuna ait karbonhidratlar içerisinde yer alan şekerler, doğada mono ve disakkarit formunda yaygın olarak bulunurlar. Monosakkaritlerin en yaygın formlarından heksozların önde gelen üyeleri ise glikoz, früktoz ve galaktozdur. Bunlar sahip oldukları aldehit veya keton gurubuna göre aldoz veya ketoz şekerler olarak da adlandırılmaktadırlar. İki monosakkaridin yani iki heksozun bir araya gelmesiyle oluşan disakkarit formundaki doğal karbonhidratlar ise sakkaroz (sükroz), maltoz ve laktozdur. Doğada bulunan mono ve disakkarit formundaki bazı önemli şekerlerin açık formülleri Şekil 1'de gösterilmiştir.

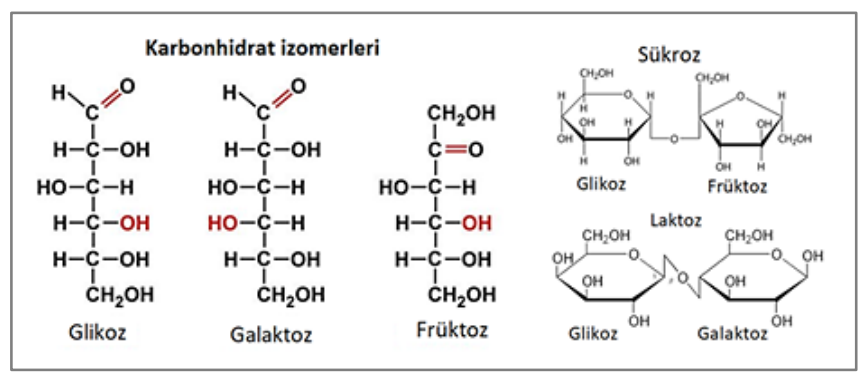

Şekil 1. Doğada bulunan bazı mono ve disakkaritlerin açık formülleri (Altınışık, 2010)

D-Tagatoz (D-tag), D-galaktozun izomeri olan doğal ve nadir bulunan bir ketoheksoz şekerdir. Siklik formu, \%79 $\alpha$-D-tagato2,6-piranoz, \%14 $\beta$-D-tagato-2,6-piranoz, \%2 $\alpha$-D-tagato-2,5furanoz ve $\% 5 \beta$-D-tagato-2,6-furanoz içerir (Oh, 2007). D-tag, tatlılık derecesi sükrozdan $\% 90$ daha yüksek olan früktozun da bir izomeridir ve tatlılık derecesi $\% 92$ sükroza eşdeğerdir. Dtagatozun \%10'luk sulu çözeltisinin ağıda soğuma etkisi düşüktür ve net fizyolojik kalori değeri ise $0.12 \mathrm{kkal} / \mathrm{g}$ 'dır. Doğal bir ketoheksoz şeker olan früktozun alternatifi daha düşük kalorili bir monosakkarit olan D-tag, halen çeşitli meşrubat türü içecekler, yoğurt, krema ve diyabetik şekerli ürünlerde tatlandırıcı olarak kullanılmaktadır (Guerrero-Wyss vd., 2018). D-tag adı verilen bu galaktoz izomerinin açık formülü, Şekil 2'de verilmiştir.

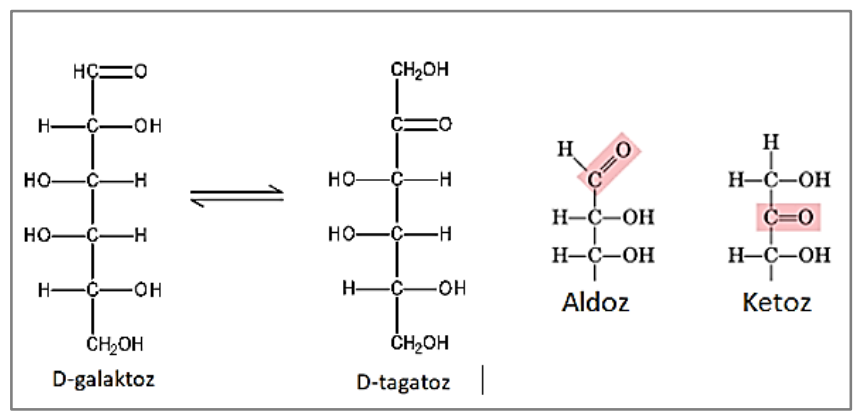

Şekil 2. D-galaktoz ve D-tagatozun açık formülleri (Khuwijitjaru vd., 2018)
Bu çalışmada, D-tagatozun gıda mühendisliği ve beslenme bilimleri açısından yeri, önemi ve potansiyel uygulama alanlarının değerlendirilmesi amaçlanmıştır.

\section{2. Özellikleri}

Bugün düşük kalorisi yanında antidiyabetik etkisi de olduğu kabul edilen D-Tagatozun ticari olarak yüksek miktarlarda üretimi, süt şekerinden elde edilen galaktozun enzimatik ya da alkali izomerizasyonu ile sağlanmaktadır. Bilindiği üzere süt ürünleri sektörünün peynir üretimi faaliyetleri sonucu yan ürün olarak önemli miktarlarda peynir altı suyu ortaya çıkmaktadır. Peynir altı suyu ise laktozca son derece zengin bir yan üründür. $\mathrm{Bu}$ sebeple, ortaya çıkan bu yan ürünün insan ve hayvan beslenmesi için tüketilebilir ürünlere dönüştürülmesi, gida sektörünün eskiden beri bilinen önemli problemleri arasında say1lmaktadır (Yetim vd. 2001). Bu noktadan hareketle, uzmanlar peynir altı suyundaki D-galaktozu, düşük kalorili D-tag'a izomerizasyon yöntemi ile dönüştürmeyi başarmışlardır (Ibrahim, 2018). D-Tag, bir gida ingrediyenti olarak Avustralya, Yeni Zelanda, Brezilya, Kore, Japonya ve Avrupa Birliği (AB) tarafından güvenli kabul edilmektedir. D-tag'ın prebiyotik, antioksidan ve ağı sağlığı dostu olmak gibi farklı sağlık ve tıbbi faydaları bulunmaktadır. Düşük kalori değeri ise D-tag'ı diyabet hastaları için güvenli bir tatlandırıcı kılmaktadır. Dünya Sağlık Örgütü (WHO), dünyada 346 milyon kişinin diyabetik olduğunu ve bu sayının \%90'ınına ise tip-2 diyabet teşhisi konulduğunu bildirmektedir. $\mathrm{Bu}$ sebeple, $\mathrm{D}$-tag, tip-2 diyabet ve obezite ile mücadelede yeni bir doğal ilaç gibi kullanılmak üzere araştırmacıların ilgisini çekmektedir (Wanarska ve Kur, 2012). Beslenme preparatı olarak D-tag'ın dünyada yeni bir pazar payı yaratacağı net şekilde görülmektedir. Kendine özgü fizikokimyasal özellikleri ve şeker alternatifi poliyol pazarı ile rekabet edebilme kabiliyeti artan ilginin başlıca sebepleri arasındadır. Dtag'ın henüz yüksek olan ticari satış fiyatının emsali ürünlerden sorbitol (1.2 dolar $/ \mathrm{kg})$ ve poliyol'ün (3-7 dolar $/ \mathrm{kg})$ birim fiyatlarına çok yakın bir değere ulaşacağı beklenmektedir. Dtag'ın birim fiyatın muadili rakip tatlandırıcılara karşı hedeflenen seviyeye ulaşabilmesi için yeterli hammadde, işletme büyüklüğü, proses optimizasyonu ve yüksek verimli biyolojik çözüm gibi bazı problemlerin aşılması gerekmektedir (Jayamuthunagai vd., 2018).

Tablo 1. D-tag fiziko-kimyasal özellikleri (Jayamuthunagai vd., 2018)

\begin{tabular}{|c|c|}
\hline Genel ad1 & Tagatoz \\
\hline Anlamdaşları & D-Tagatoz, a-D-Tagatoz, D-likso-heksuloz \\
\hline Molekül Formülü & $\mathrm{C}_{6} \mathrm{H}_{12} \mathrm{O}_{6}$ \\
\hline CAS numarası & $87-81-0$ \\
\hline Sinifi & Karbonhidrat monosakkarit ketoheksoz \\
\hline Yap1s1 & 3 kiral karbonlu; C-4 epimer D-früktoz \\
\hline Molekül Ağırlığ & 180 \\
\hline Fiziki görünümü & Anhidroz kristal katı \\
\hline Renk & Beyaz \\
\hline Koku & Kokusuz \\
\hline Tat & Yoğun tatlı \\
\hline Suda çözünürlük & $160 \mathrm{~g} / 100 \mathrm{ml} \mathrm{H}{ }_{2} \mathrm{O}, 20{ }^{\circ} \mathrm{C}$ \\
\hline Etanolde çözünürlük & $0.02 \mathrm{~g} / 100 \mathrm{ml} \mathrm{H}{ }_{2} \mathrm{O}, 22{ }^{\circ} \mathrm{C}$ \\
\hline Erime noktas1 & $134^{\circ} \mathrm{C}$ \\
\hline Çözünürlük Isısı & $42.3 \mathrm{~kJ} / \mathrm{kg}, 20^{\circ} \mathrm{C}$ \\
\hline Bozulma sıcaklığ1 & $120^{\circ} \mathrm{C}$ \\
\hline pH stabilitesi & $2-7$ \\
\hline Göreceli tatl1l1k derecesi & $\% 92$ sükroz eşdeğeri \\
\hline
\end{tabular}




\begin{tabular}{l|l}
\hline Tatlılık & $\begin{array}{l}\text { Sükroz benzeri; ancak, früktoz gibi daha hızlı } \\
\text { lgıllanır }\end{array}$ \\
\hline Emilim oranı & $\% 25$ \\
\hline Rölatif enerji değeri & 13 kalori sükroz eşdeğeri \\
\hline Kalori değeri & $0.12 \mathrm{kkal} / \mathrm{g}$ \\
\hline Kanserojenlik & Bildirilmemiş \\
\hline Lezzet geliş̧iricilik özelliği & $\begin{array}{l}\text { Yoğun tatlılı ile birlikte lezzetlendirici } \\
\text { özellikli }\end{array}$ \\
\hline Nemlendiricilik & Sorbitol benzeri \\
\hline Karamel oluşumu & $\begin{array}{l}\text { Evet, yüksek sıaklıkta kahverengimsi } \\
\text { sükroza dönüşür }\end{array}$ \\
\hline
\end{tabular}

\section{Uygulama Alanları}

Şeker üretimi kavramı, endüstriyel boyutta başlangıcı olan 17.yüzyıldan günümüze kadar üretimi, tüketimi ve uygulama alanları bakımından dikkat çekici ilerleme gösteren alanlardan birisi olmuştur. Şekerlerle ilgili bilimsel araştırmalar günümüzde de devam etmektedir ve örneğin, nadir (rare) şekerlerin bireylerde farklı algılama yolaklarını harekete geçirdiği ve vücutta yeni (novel) fizyolojik işlevleri ortaya çıkardığı bulunmuştur. Uluslararası Nadir Şekerler Topluluğu (ISRS) tarafından yapılan tüm heksozları ve pentozları içeren sınıflandırmaya göre, 20 adet heksoz ve 9 adet pentoz olmak üzere toplam 29 adet nadir şeker tanımlanmış ve bunların geniş uygulama potansiyellerinin bulunduğu rapor edilmiştir (Kawamura, 2004; Jayamuthunagai vd., 2018). Buradan hareketle D-tag'ın gıda ürünlerinde kullanımı ve uygulamalarına ilişkin örnekler Tablo 2'de gösterilmiştir.

Nadir şekerlerin üretimi, fermantasyon teknolojisi, moleküler biyoloji, enzim teknolojisi ve organik kimya kullanımı gibi çok disiplinli yaklaşımlar gerektirir. İlk defa Spherix firması tarafından 1990'lı yıllarda sentezlenen D-tag, düşük kalorili tatlandırıcı olma özelliği ile tanındı. Tagatozun sükrozdan fazla ayırt edilemeyen tadı, bu nadir şekerin fiziksel, kimyasal ve biyolojik özelliklerinin anlaşılması bakımından araştırmacıların artan ilgisini çekmeyi başarmıştır (Levin, 2002; Jayamuthunagai vd., 2018).

Nadir şekerlerin üretimi, fermantasyon teknolojisi, moleküler biyoloji, enzim teknolojisi ve organik kimya kullanımı gibi çok disiplinli yaklaşımlar gerektirir. İlk defa Spherix firması tarafindan 1990'lı yıllarda sentezlenen D-tag, düşük kalorili tatlandırıcı olma özelliği ile tanındı. Tagatozun sükrozdan fazla ayırt edilemeyen tadı, bu nadir şekerin fiziksel, kimyasal ve biyolojik özelliklerinin anlaşılması bakımından araştırmacıların artan ilgisini çekmeyi başarmıştır (Levin, 2002; Jayamuthunagai vd., 2018).

Tablo 2. D-tag'ın gida ürünlerinde kullanımı ve uygulamalarl (Jayamuthunagai vd., 2018).

\begin{tabular}{l|c}
\hline Gıda ürünü & $\begin{array}{c}\text { Konsantrasyonu } \\
\text { (Takriben) }\end{array}$ \\
\hline Çedar peyniri & $2 \mathrm{mg} / \mathrm{kg}$ \\
Ciklet & $\% 60(\mathrm{w} / \mathrm{w})$ \\
Çikolata & $\% 15(\mathrm{w} / \mathrm{w})$ \\
Şekerleme & $\% 15(\mathrm{w} / \mathrm{w})$ \\
Diyet içecekleri & $\% 1(\mathrm{w} / \mathrm{w})$ \\
Diyet takviyeleri & $\% 90(\mathrm{w} / \mathrm{w})$ \\
Feta peyniri & $17 \mathrm{mg} / \mathrm{kg}$ \\
Frosting tatlı & $\% 15(\mathrm{w} / \mathrm{w})$ \\
Norveç Gjetost peyniri & $15 \mathrm{mg} / \mathrm{kg}$ \\
Dondurma & $\% 3(\mathrm{w} / \mathrm{w})$ \\
Laksatifler & $6500 \mathrm{mg} / \mathrm{kg}$
\end{tabular}

\begin{tabular}{l|c} 
Ambalajlı kahvaltılık gevrekler & $\% 15(\mathrm{w} / \mathrm{w})$ \\
Parmesan peyniri & $10 \mathrm{mg} / \mathrm{kg}$ \\
İnek sütü tozu & $800 \mathrm{mg} / \mathrm{kg}$ \\
Rokfor peyniri & $20 \mathrm{mg} / \mathrm{kg}$ \\
Pastörize/UHT inek sütü & $2-3000 \mathrm{mg}(\mathrm{kg}$ \\
Yoğurt & $29 \mathrm{mg} / \mathrm{kg}$ \\
\hline
\end{tabular}

D-tag henüz geniş bir endüstriyel uygulama alanına sahip olmamasına rağmen diğer bazı şekerler (sükroz, glikoz ve früktoz) gibi düşük kalorili tatlandırıcı ve besleyici madde olarak gıda ürünlerinin ekserisinde, içeceklerde, diyet takviyelerinde ve hatta çürük önleyici diş macunu (noncariogenic) ve ağız solüsyonlarının üretiminde kullanıldığı bildirilmektedir (Oh, 2007).Ayrıca, D-tag yüksek tatlılık derecesi, düşük kalorisi, düşük glisemik indeksi ve gıda formülasyonları bakımından istenen fiziko-kimyasal özellikleri (hacim artırıcı, tekstür geliştirici, nemlendiricilik ve stabilizatör) ile gelecek vaat eden bir bileşiktir. D-tag'ın diğer avantajlı özelliklerinden birisi de prebiyotik işlevine sahip oluşudur. Özellikle kalın bağırsakta fermente olabilme kabiliyeti, intestinal epitelyal hücreler için önemli metil bütiratın yüksek kosantrasyonlarda üretilmesini olanaklı kılmakta ve bu yolla kolon kanserine karşı koruyuculuk sağlamaktadır (Roy vd., 2018).

Laktoz türevi maddeler arasında D-tag, gıda endüstrisinde bugün fazla miktarda kullanım potansiyeline sahip maddelerden birisidir. Tatlılık derecesi bakımından sükroza olan yakınlığı (\%92), soğuma etkisinin olmaması, güçlü aromatik yansıması ve stevyadan farklı olarak tat algısının uzun süreli veya kalıcı olmaması D-tag'ın üstün avantajları arasında sayılmaktadır (Guerrero-Wyss vd., 2018).

D-tag'ın kimyasal özellikleri, mükemmel biyolojik toleransı ile birleştiğinde, araştırmacıların ve ticari kuruluşların ilgisini neden bu derece çektiğini açıklamaktadır. Yine D-tag bir indirgen şekerdir. Bu yönüyle Maillard reaksiyonunda aktivitesi son derece yüksek olup, unlu mamullerin isıl işlem esnasında non-enzimatik esmerleşmesinde önemli rol oynar. Bunun neticesi olarak da Dtag, şekerleme endüstrisinde ayırt edici ve baskın karamel ve/veya malt aromaları yaratmak amacıyla kullanılmaktadır. Ayrıca, yoğurt ve meşrubat türü yumuşak içeceklerde, mükemmel çözünürlüğü sayesinde $\left(\% 58 \mathrm{w} / \mathrm{w}, 21^{\circ} \mathrm{C}\right)$ aspartam, asesülfam potasyum, sakkarin ve sükraloz gibi yüksek yoğunluklu tatlandırıcı karışımlarında tat etkisini geliştirir. Formülasyona $\% 0.2$ ila \%1 seviyesinde ilave edildiği takdirde, ağızda kalan tadı iyileştirmekte, ilave tatlandırıcılardan kaynaklanan tat algısını ve kalıcı tat hissini de azaltmaktadır. Diğer taraftan, özellikle yoğurt ürünlerinde D-tag ve probiyotik etkileşiminin ileri mikrobiyolojik ve biyokimyasal araştırmalar ile daha fazla değerlendirilmesi gerektiği bildirilmektedir (Torrico vd., 2019).

Diyabetik tat olarak bilinen tatlandırıcıların (örneğin asesülfam potasyum) yavaş ancak uzun süren metalik veya acımsı tadı, D-tag ile etkili şekilde maskelenebilir. Bu durum, yumuşak içeceklerin aspartam ve diğer tatlandırıcıların degrade olmalarından kaynaklanan raf ömrünün duyusal kıstaslar bakımından uzamasına olanak verir (Ensor vd., 2015). D-tag, laktoz veya maltodekstrozdan farklı olarak, düşük kalorisi ile yoğun tatlı (şekerli) içeceklerde ağız ve diş sağlığını koruyacak şekilde kullanılabilir. Ancak, bugün D-tag'ın birim fiyatının 8.813.2 dolar $/ \mathrm{kg}$ aralığında olması, düşük kalorili gıdalarda kullanımını maliyet dezavantajı sebebiyle önemli derecede engellemektedir. Generally recognized as safe (GRAS) statüsüne rağmen Gıda Katkı Maddelerine ilişkin Ortak FAO-WHO Uzman Komitesi Raporu (JECFA) ve G1da Bilimsel Komitesi (SCF), D- 
tag'ın kullanılabileceği gıda ürünlerini ve müsaade edilen kullanım sınırını, karbonatlı içeceklerde \%1, unlu mamullerde $\% 2$, sert şekerlemeler ve kahvaltılık gevreklerde $\% 15$, çikolatada $\% 25$ ve çiklette $\% 60$ olarak belirlemiştir. Diğer taraftan D-tag, süt ürünlerine prebiyotik özellik taşıdığı için eklenmektedir. Günlük alım miktarı sadece birkaç gram (3-5 g/porsiyon) olup, formüle $\%$ 0.2-1 oranında eklendiğinde diyet meyveli yoğurt ürünlerinin tadını olumlu yönde arttırmaktadır. D-tag'ın 2009 yılı üretim miktarı 900 ton ve pazar değeri 1.3 milyar dolardır (Paterson ve Kellam, 2009), bunu dışında alanyazında daha güncel bir veriye rastlanamamiştır.

Küresel toplam tatlandırıcı pazarının 2015 yılından sonra 20 ila 30 bin ton arası üretim miktarına ve 37.5 milyar dolar büyüklügüüne ulaşacağı ve bu pazarın 2024 yılı itibariyle toplam 82.6 milyar dolara kadar çıkacağı öngörülmektedir (transparencymarketresearch.com). Pazarın baskın tatlandırıcısı ise 2018 y1lı verilerine göre \%77.2 oranı ile sükrozdur. Düşük kalorili tatlandırıcılar içeren ve glisemik indeksi düşük yiyecek ve içecek tüketimi, tüm dünyada 2016 y1lı itibariyle 9 milyar dolardan fazla gerçekleşmiştir. Küresel ölçekte en önde gelen Dtag üreticileri sirasiyla: Nunaturals, Damhert Nutrition, ChromaDex, CJ Cheiljedang Corporation, Sigma-Aldrich Co. LLC ve Alfa Aesar firmalarıdır (Sokołowska vd., 2021).

Ayrıca, son çalışmalar, D-Tagatozun tarım sektöründe bitki hastalıkları ile mücadelede antifungal agrokimyasal olarak kullanılabileceğini de göstermektedir. D-tag, bitkilerde bazı fitopatojenlerin gelişimini baskılamaktadır. Bu sebeple, özellikle domates, patates ve patlicanda Phytophthora. infestans, salatalıkta Pseudoperonospora cubensis, üzümde Plasmopara viticola, buğdayda Puccinia recondita ve pirinçte ise Pythium graminicola ve Pythium aphanidermatum ile mücadelede son derece etkili çözümler sunabilmektedir (Chaded vd., 2020).

\section{4. Üretim Süreçleri}

D-tag, bitkisel veya hayvansal kaynaklarda doğal olarak çok az veya yeteri kadar bulunmadığı için laktoz kökenli galaktozun izomerizasyonu ile kimyasal ya da enzimatik yöntemlerle üretilmektedir. Elbette her iki yönteminde bazı avantaj ve dezavantajları bulunmaktadır. D-tag üretimi için gerekli olan ön madde galaktozdur ve bunun da doğada en çok bulunduğu kaynak süt şekeri, laktozdur. Tagatoz üretimi amacıyla kullanılan ve Dünya süt ve süt ürünleri sektörünün en önemli yan ürünlerinden peynir altı suyunun yıllık üretimi 200 milyon ton civarındadır. Buradan üretilen süt şekeri galaktozun (laktozun parçalanma ürünü) ticari D-Tagatoza dönüştürülmesi, gıda sektörü için önemli bir çıkış yolu olarak görülmektedir.

\subsection{Kimyasal Süreç}

Tagatoz üretiminde laktoz, önce hidroliz yoluyla glikoz ve galaktoza ayrıştırılmaktadır. Daha sonra galaktoz da alkali koșullar altında enolizasyon reaksiyonuna (bir ketonun bir enol haline dönüştürülmesi işlemi) tabi tutulmakta ve kalsiyum hidroksit $(\mathrm{CaOH})$ yardımıyla izomerleştirilerek D-tagatoz elde edilmektedir. Ham şeker ve kimyasal gida katkıları bir reaksiyon kazanında karıştırılmakta ve dönüşüm reaksiyonunun gerçekleşmesi için yüksek sicaklıkla muamele edilmektedir. Reaksiyonun bitiminde de oluşan üründeki tuzlar giderildikten sonra kromatografik yöntemle hedef ürün ayrıştırılmaktadır. Son ürün konsantre şurup (syrup) ya da kristallendirme ile katı formda da üretilebilmektedir (Y1lmaz-ersan vd., 2016; Shintani, 2019; Sokołowska vd., 2021). D-galaktozun alkali çözeltide D-tagatoz e-ISSN: 2148-2683 ve D-taloza izomerizasyonu Şekil 3'de şematize edilerek gösterilmektedir.

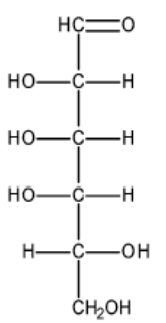

D-Talose

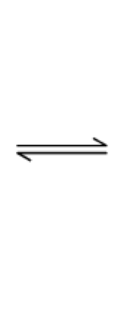

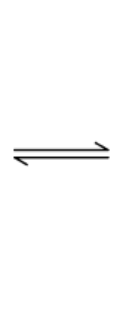

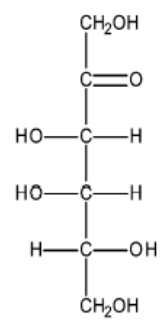

D-Tagatose
Şekil 3. D-galaktozun alkali çözeltide D-tagatoz ve D-taloza izomerizasyonu (Khuwijitjaru vd., 2018)

\subsection{Kimyasal Süreç}

D-tag'ın enzimatik olarak üretiminde ise kimyasal yöntemden farklı olarak, genellikle Thermotoga türü mikroorganizmalardan elde edilen enzimler (Polyol dehidrogenaz, L-Arabinoz izomeraz, D-Galaktoz izomeraz vb.) kullanılır. Bu enzimler, galaktitol, früktoz veya D-galaktozu, Dtagatoz'a katalize ederek substratın (ön madde, örneğin Dgalaktoz) hedef bileşene (D-tagatoz) dönüşümünü sağlamaktadırlar (Shintani, 2019).

D-tag'ın enzimatik yöntemlerle üretilmesi kullanılan substrat ve enzimin türü ile gerçekleşen reaksiyon mekanizmasına göre değişiklikler gösterebilmektedir. Örneğin, substrat olarak galaktoz kullanılması durumunda, L-Arabinoz izomeraz veya DGalaktoz izomeraz enzimleri katalizör olarak kullanılır ve bunlar da farklı verim ve reaksiyon süreleri gerektirmektedir. Eğer substrat früktoz seçilirse, bir dizi enzimatik reaksiyon ile aşamalı olarak D-tag elde edilmektedir. Galaktitolden D-tag sentezi de yine kendine özgü farklı verim-reaksiyon süre gereksinimine sahiptir. D-tag'ın enzimatik üretiminde kullanılan substratlar, kullanılan enzimler ve reaksiyonları ile elde edilen farklı verim ve reaksiyon süreleri Tablo 3'de sunulmuştur (Khuwijitjaru vd., 2018; Ibrahim, 2018). Verilere göre, D-tag'ın üç farklı substratdan üretilmesi mümkün olup, verimlilik ve reaksiyon süresi açısından ise früktoz ve galaktitol çevrimlerinin daha başarılı oldukları anlaşılmaktadır (Tablo 3). Enzimatik işlemler sonucu ortaya çıkan yeni ürün ayrıştırılarak saflaştırılmakta ve ambalajlanarak satışa hazır hale gelmektedir.

Tablo 3. D-tag üretiminde kullanılan substratlar, enzimler, reaksiyonlar ve verim-süre bulguları (Khuwijitjaru vd., 2018)

\begin{tabular}{l|l|c}
\hline Substrat & Enzim/Reaksiyon & $\begin{array}{c}\text { Verim (Reaksiyon } \\
\text { süresi) }\end{array}$ \\
\hline \multirow{4}{*}{ Galaktoz } & L-Arabinoz izomeraz & $\begin{array}{c}\% 16.2 \text { (48 saat) } \\
\% 22.3 \text { (14 saat) } \\
\% 79.7 \text { (48 saat) } \\
\% 55 \text { (3 saat) }\end{array}$ \\
& D-Galaktoz izomeraz & \\
\hline \multirow{5}{*}{ Früktoz } & (1) Früktozun früktoz-6-fosfata & \\
& hekzokinaz enzimi ile fosforilasyonu, & \\
& (2) Früktoz-6-fosfatın tagatoz-6- & \\
& fosfata früktoz-1,6-bifosfat aldolaz & $\% 96.3$ (16 saat) \\
& enzimi ile epimerizasyonu ve (3) & \\
& tagatoz-6-fosfatın tagatoza fitaz & $\% 30$ (3 saat) \\
\cline { 2 - 3 } & enzimi ile defosforilasyonu & $\% 91$ (15 saat) \\
\cline { 2 - 3 } Galaktitol & Heksuronat C-4-epimeraz & Polyol dehidrogenaz \\
\hline
\end{tabular}




\section{Metabolizması}

İnsan vücudu; ihtiyaca ve mevcuda göre şeker, yağ veya protein yakar, öncelikle şekeri tercih eder ancak hangisinin yolağ 1 o anda etkinse diğeri askıya alınır. Karbonhidrat metabolizmasında öncelikle glikoz kullanılır ve bu şeker, organizmanın en önemli enerji kaynağıdır. Ayrıca vücuda alınan ve hücre içerisine giren glikozun tamamı hemen enerji için kullanılabilir ya da depolanır. Oral yoldan alınan D-tag'ın ise yalnızca \%20'si, özellikle karaciğerde, metabolize olabilmektedir. Deney hayvanları ve pre-klinik araştırmalara göre, D-tag glikoz seviyesini de düşürmektedir. Zaten D-tag bu yönüyle bilim dünyasının dikkatini çekmiştir. Gözlemlerde ulaşılan sonuç, glikoz seviyesini düşürme mekanizmasının, Dtag'ın karbonhidrat emilimini intestinal disakkaritler ile glikozun taşınmasını baskılayarak müdahale ettiği yönündedir. D-tag aynı zamanda hepatik glikojenolizi de baskılamaktadır. İlaveten, sükroz ile mukayese edildiğinde, D-tag toplam kolesterol, VLDL ve LDL'yi azaltma, HDL'yi ise arttrrma yönünde bir etki de göstermektedir (Guerrero-Wyss vd., 2018).

Tagatoz’un kolesterol düşürücü etki mekanizmasının glikoliz kaynaklı prüvat oluşumunu ya da kolesterol ve yağ asiti biyosentez prekürzörü de olan Kreps döngüsü içindeki asetilCoA'y1 azaltarak yaptığ1 düşünülmektedir (Muddada, 2012). Ayrıca, Muddada (2012), D-tag'ın früktozun gut tarafindan emilimini bloke ettiğini ve bu suretle de diyet kaynaklı dislipidemiyi etkili biçimde düşürdüğünü bildirmektedir. $\mathrm{Bu}$ sebeple, D-tag'nn diyet yönetimi açısından obezite ile mücadelede çok önemli bir rol oynayacağı öngörülmektedir. Çünkü ince bağırsakta früktozu aktaran taşıyıcılar, D-tag için afinite göstermemekte, tüketilen D-tag'ın yalnızca \%20'si ince bağırsakta emilmekte ve devamında karaciğerde früktozdan çok daha yavaş bir hızla metabolize edilmektedir.

Sindirilmemiş D-tag ise diğer sindirimi düşük karbonhidratlarda olduğu gibi (diyet lifi vb.), kalın bağırsakta mikroflora tarafindan fermente edilebilmektedir. Fermantasyon neticesinde ortamda kısa zincirli yağ asitleri (SCFA) ve özellikle de bütirat, üretilmektedir. Bütirat, kolon kanserini önlemede rol oynayan önemli mikrobiyal metabolitler arasındadır (Wu vd., 2010). Ayrıca, D-tag, ince bağırsakta sükraz ve maltaz enzimlerini de baskıladığ 1 için sükroz ve maltozun sindirim ve emilimini de sinırlamaktadır (Buemann vd., 2000; Sokołowska vd., 2021). Bu mekanizma da yine obezite ile mücadelede rol oynayabilecek önemli bir araç olacaktır.

\section{Toksitesi}

D-tag, insanlar tarafindan vücutta sentezlenemeyen, doğada nadir bulunan ve düşük glisemik indeks değerine sahip bir şekerdir. Araştırmalar, D-tag'ın glikoz metabolizmasını regüle edebildiğini ve bu sayede özellikle diyabetik hastalarda glikoz homeostazını koruduğunu göstermektedir. Bu durum, insülin yanıtının da iyileşeceğini ve sonuç olarak ise hipergliseminin daha etkin ve daha iyi kontrol edileceğinin göstergesidir. D-tag'ın toksik etkileri ile ilgili literatürde henüz bir çalışma rapor edilmemiştir. Yalnızca, eksik emilim kaynaklı olarak ortaya çıkan ve orta düzeyde bazı sindirim sorunlarına (mide bulantısı, gaz, şişkinlik, diyare gibi) yol açabileceği bildirilmiştir (Sokołowska vd., 2021).

\section{Sonuç}

Süt şekeri laktozdan üretilen galaktozun ticari D-tag'a farklı süreçlerle dönüştürülmesi, gıda endüstrisi bakımından potansiyel firsatlar sunmakta ve süt endüstrisi için adeta çıkış yolu gibi gözükmektedir. Araştırmalar, D-tag'ın diğer yapay tatlandırıcılara göre daha üstün fiziko-kimyasal özellikleri ile bazı metabolik avantajlarının olduğunu göstermektedir. Şöyle ki Dtag, gıda endüstrisi ve sağlık sektörü için diğer şekerler ve alternatif tatlandırıcılara göre, yeni firsatlar sunmaktadır. Çünkü D-tagatoz, son yıllarda şeker tüketimine bağlı olarak artan obezite, diyabet, ağız-diş sağlığı ve sindirim sistemi sorunlarına karşı alternatif bir tatlandırıcı olarak öne çıkmaktadır. Sağlıklı ve doğal beslenme açısından getireceği faydaların dışında Dünya yapay tatlandırıcı pazarının ciro büyüklüğü de dikkate alındığında D-tag'ın, alternatif tatlandırıcı ve prebiyotik sektörleri için itici bir güç olacağını ifade etmek pek hatalı olmayacaktır. Özetle, Dtag'ın çok disiplinli olarak farklı özelliklerinin araştırılması ve gözlenen faydalarından hedef kitlelerin istifade edebilmesi için çok daha ileri düzeyde çalışmalara gerek olduğu değerlendirilmektedir. Sonuç olarak, D-tag'ın gıda ve sağlık sektörüne getirebileceği avantajların ülkemizde de bilinmesi/tanınması çok önemli firsatları beraberinde getirecek ve özellikle süt sanayinin potansiyel sorunlarının çözümüne katkı sunacaktır.

\section{Kaynakça}

Altınışı, M. (2010). Karbonhidrat metabolizması bozukluklarına biyokimyasal yaklaşım. ADÜ Tıp Fakültesi Dergisi, 11(1), 51-59.

Buemann, B., Toubro, S., Raben, A., Blundell, J. and Astrup, A. (2000). The acute effect of D-tagatose on food intake in human subjects. British Journal of Nutrition, 84 (2), 227-231.

Chahed, A., Nesler, A., Navazio, L., Baldan, B., Busato, I., Ait Barka, E., . . . and Perazzolli, M. (2020). The Rare Sugar Tagatose Differentially Inhibits the Growth of Phytophthora infestans and Phytophthora cinnamomi by Interfering With Mitochondrial Processes. Frontiers in Microbiology, 11, Article 128.

Ensor, M., Banfield, A. B., Smith, R. R., Williams, J. and Lodder, R. A. (2015). Safety and Efficacy of D-Tagatose in Glycemic Control in Subjects with Type 2 Diabetes. Journal of endocrinology, diabetes \& obesity, 3 (1), 1065.

Guerrero-Wyss, M., Durán Agüero, S. and Angarita Dávila, L. (2018). D-Tagatose Is a Promising Sweetener to Control Glycaemia: A New Functional Food. BioMed Research International, 2018, 1-7.

Ibrahim, O. (2018). A New Low Calorie Sweetener D-Tagatose from Lactose in Cheese Whey as a Nutraceutical ValueAdded Product. Food Health and Technology Innovations, 1 (1), 11-28.

Jayamuthunagai, J., Gautam, P., Srisowmeya, G. and Chakravarthy, M. (2017). Biocatalytic production of Dtagatose: A potential rare sugar with versatile applications. Critical Reviews in Food Science and Nutrition, 57 (16), 3430-3437.

Kawamura, Y. (2004). D-Tagatose Chemical and Technical Assessment (CTA), FAO.

Khuwijitjaru, P., Milasing, N. and Adachi, S. (2018). Production of D-tagatose: a review with emphasis on subcritical fluid treatment. Science, Engineering and Health Studies, 12 (3), 159-167. 
Levin G. V. (2002). Tagatose, the new GRAS sweetener and health product. Journal of medicinal food, 5 (1), 23-36.

Muddada, S. (2012). Tagatose: the multifunctional food ingredient and potential drug. Journal of Pharmacy Research, $5(1), 626-631$.

Oh, D. K. (2007). Tagatose: properties, applications, and biotechnological processes. Applied Microbiology and Biotechnology, 76 (1), 1-8.

Paterson, A. and Kellam, S. (2009). Transformation of lactose for value-added ingredients. Dairy-Derived Ingredients, Vol? 625-643.

Roy, S., Chikkerur, J., Roy, S. C., Dhali, A., Kolte, A. P., Sridhar, M. and Samanta, A. K. (2018). Tagatose as a Potential Nutraceutical: Production, Properties, Biological Roles, and Applications. Journal of Food Science, 83 (11), 2699-2709.

Shintani, T. (2019). Food Industrial Production of Monosaccharides Using Microbial, Enzymatic, and Chemical Methods. Fermentation, 5 (2), 47.

Sokołowska, E., Sadowska, A., Sawicka, D., Kotulska-Bąblińska, I. and Car, H. (2021). A head-to-head comparison review of biological and toxicological studies of isomaltulose, dtagatose, and trehalose on glycemic control. Critical Reviews in Food Science and Nutrition, Vol: 1-26.

Taylor, S. L., Lambrecht, D. M. and Hefle, S. L. (2005). Tagatose and milk allergy. Allergy, 60 (3), 412-413.

Torrico, Tam, Fuentes, Viejo and Dunshea. (2019). D-Tagatose as a Sucrose Substitute and Its Effect on the Physico-Chemical Properties and Acceptability of Strawberry-Flavored Yogurt. Foods, 8 (7), 256.

Wanarska, M. and Kur, J. (2012). A method for the production of D-tagatose using a recombinant Pichia pastoris strain secreting $\quad \beta$-D-galactosidase from Arthrobacter chlorophenolicus and a recombinant $\mathrm{L}$-arabinose isomerase from Arthrobacter sp. 22c. Microbial Cell Factories, 11 (1), 113.

Wu, T., Rayner, C. K., Jones, K. and Horowitz, M. (2010). Dietary Effects on Incretin Hormone Secretion. Vitamins \& Hormones, 84 (C), 81-110.

Yetim, H., Müller, W.D. and Eber, M. 2001. The Possibility of Using Fluid Whey in Comminuted Meat Products: effects on the technological, chemical and sensory properties of frankfurter type sausages. Food Res. Int. 34 (2/3): 97-101.

Yılmaz-ersan, L., Özcan, T., Akpınar-bayizit, A. ve Delikanlı, B. (2016). Bifidojenik Faktör Olarak Laktoz Türevlerinin Önemi. Uludağ Üniversitesi Ziraat Fakültesi Dergisi, 30 (2), 79-90. 